\title{
Mechanical properties of solid glass bricks
}

\author{
Jiří Fíla ${ }^{1}$, Martina Eliášová ${ }^{2}, Z_{\text {deněk Sokol }}^{3}$ \\ Faculty of Civil Engineering, Czech Technical University in Prague, Prague, Czech Republic \\ E-mail: 1jiri.fila@fsv.cvut.cz (corresponding author)
}

\begin{abstract}
Glass as one of the oldest building materials has been used for centuries to fill window openings. In recent years is it increasingly used also for load-bearing structural elements such as beams, columns, ribs, railings, etc. In addition to flat glass and hollow glass blocks, which have been used historically for non-load-bearing partitions and facades, new load bearing structures from solid glass bricks are arising. Their greater use is hampered by a lack of knowledge of their material properties. Also, their joining is difficult, as can be seen from the realized structures and published works focused on the glass bricks masonry. Most often, transparent adhesives or special mortars are used on the joint between glass bricks.

In addition to some examples of completed glass brick structures, the paper is aimed at determining the material properties of glass bricks, which are a prerequisite for the design of safe structures. Two sets of experiments were performed. There were made three-point bending tests and compression tests to determine the bending tensile strength, modulus of elasticity and compressive strength of glass bricks.
\end{abstract}

Keywords: solid glass blocks, compression test, three-point bending test, modulus of elasticity.

\section{Introduction}

Over the past ten years, several buildings have been built using solid glass bricks. In most of these realizations the bricks do not fulfill the load-bearing function so additional supporting structure is needed. An exception is the Crystal House in Amsterdam (Oikonomopoulou, Bristogianni, Veer, \& Nijsse, 2017) and the Atocha Monument in Madrid (Christoph \& Knut, 2008). These projects use custom-made bricks, whose price is undoubtedly higher than in mass production. At present, full glass bricks are marketed by two manufacturers (glass brick Poesia and Vetropieno), which differ slightly in color, surface finish and geometric dimensions.

Experimental research performed in the laboratories of the Faculty of Civil Engineering, CTU in Prague was focused on the verification of the material properties of solid glass Vetropieno bricks. This is the first stage of the experiments, the results of which will then be used in numerical modeling of glass brick masonry. The aim of research is to create a similar masonry with traditional one using of these bricks. The brick shape is tapered to allow easy remove of the finished brick from the mould (see Figure 1 and Figure 2). This paper describes three-point bending tests and compression tests to determine the tensile bending strength, modulus of elasticity and compressive strength of glass bricks. These experiments are part of a long-term research on glass brick masonry, see. (Fíla, Eliášová, \& Sokol, 2017, 2018).

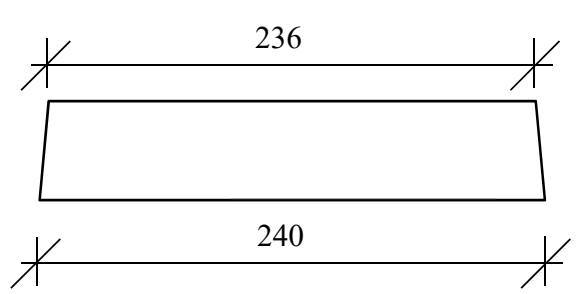

(a)

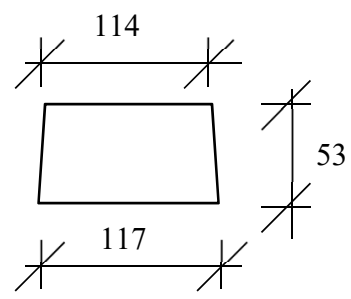

(b)

Figure 1. Geometrical dimensions of the brick: (a) - front view; (b) - side view

(C) 2019 Authors. Published by VGTU Press. This is an open-access article distributed under the terms of the Creative Commons Attribution (http://creativecommons.org/licenses/by/4.0/) License, which permits unrestricted use, distribution, and reproduction in any medium, provided the original author and source are credited. 


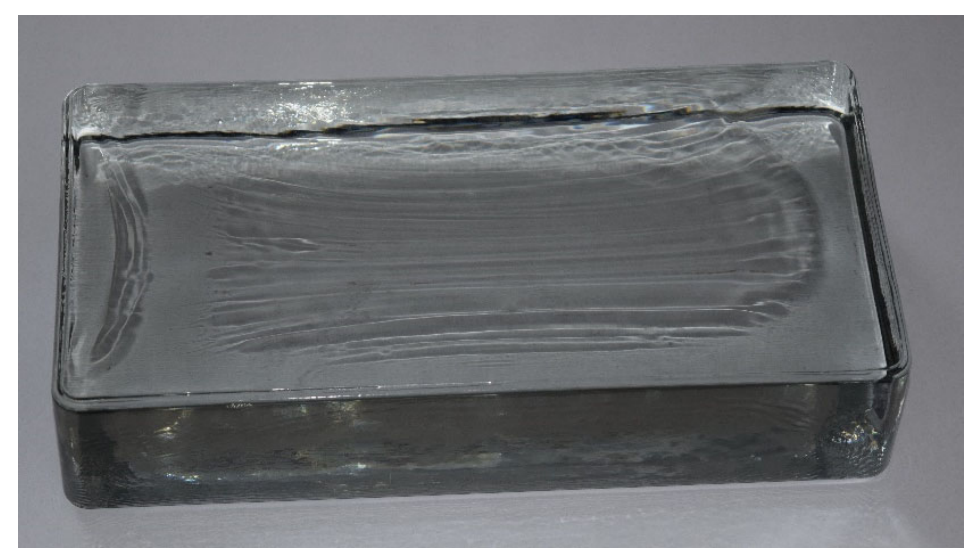

Figure 2. Solid glass brick

\section{Experiments}

\section{Three-point bending flexural test}

Three-point bending test were done on MTS Qtest 100 testing machine (maximum load $100 \mathrm{kN}$ ). The tested brick was placed in the testing machine in horizontal position as shown in Figure 3 and Figure 4. Because of risk of the breakage due to the local peak stress, there were placed rubber pads between the glass brick and the supporting steel plate. The thickness of the rubber pads was $5 \mathrm{~mm}$. The steel plates were supported by steel rods with diameter of $20 \mathrm{~mm}$. The force was applied through the steel rod and plastic plate. The load point was in the middle of the span and the rubber pad was also placed between the steel and glass surface.

The vertical deformations over the supports were measured by linear variable displacement transducers (LVDTs). The displacement in the middle of the span was measured by laser extensometer. Real brick deflection was calculated by subtracting the average of support values from the middle-span value. In addition to the deflection measurement, normal stress in the middle of the span at the bottom side was determined. For this purpose strain gauges LY 1110 / 120 were used, which were placed on the tensile surface of the test specimen. The loading was controlled by displacement and the loading rate was set to $0.5 \mathrm{~mm} / \mathrm{min}$. Totally six bricks were tested.

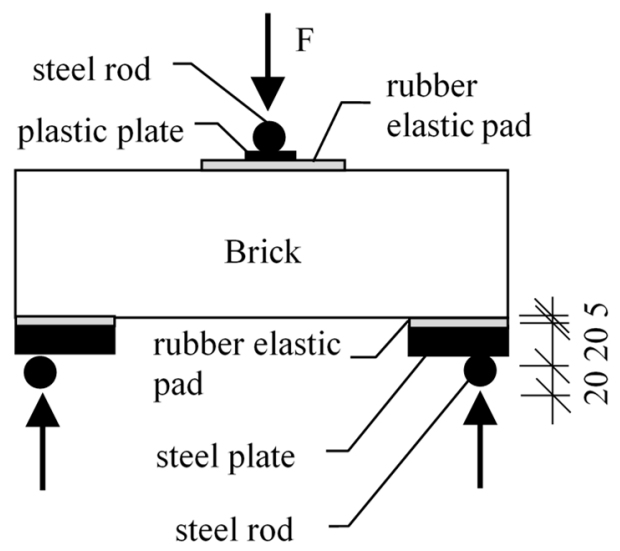

Figure 3. Test schema

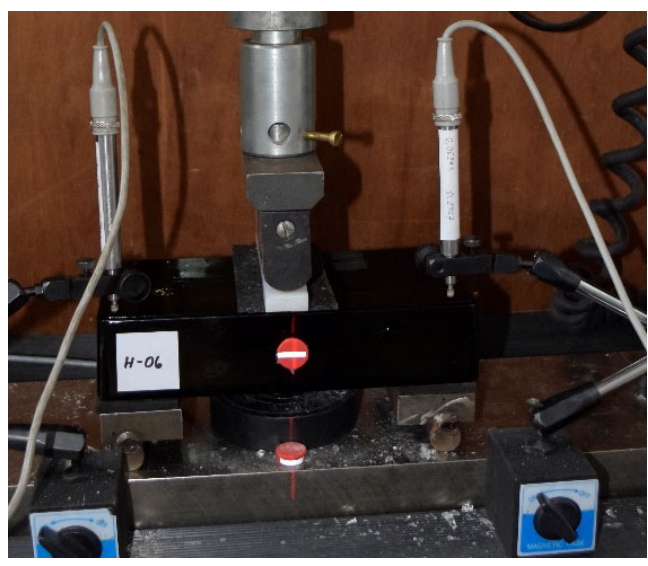

Figure 4. Specimen the testing machine

\section{Compression test}

Compression test were done on VEB EDB 400 testing machine which can exert maximal force $4000 \mathrm{kN}$. Glass bricks have a concave upper surface due to shrinkage in the course of cooling during manufacturing, and their shape is tapered as mentioned above. Because of this it was necessary during the compression test to lay the brick in the gypsum bed on the bottom and top surfaces to obtain uniform stress redistribution. For easier and quicker handling, it was decided to place glass brick between steel plates, see Figure 5. Tests were made two weeks after preparing of the specimens. During the test, only the maximum force was measured. Figure 6 shows the specimen in the testing machine. The loading was controlled by displacement and the loading rate was set to $1 \mathrm{~mm} / \mathrm{min}$. Compressive strength is declared by the manufacturer, so this test was performed just for check of the declared parameter. Totally three specimens were tested. 

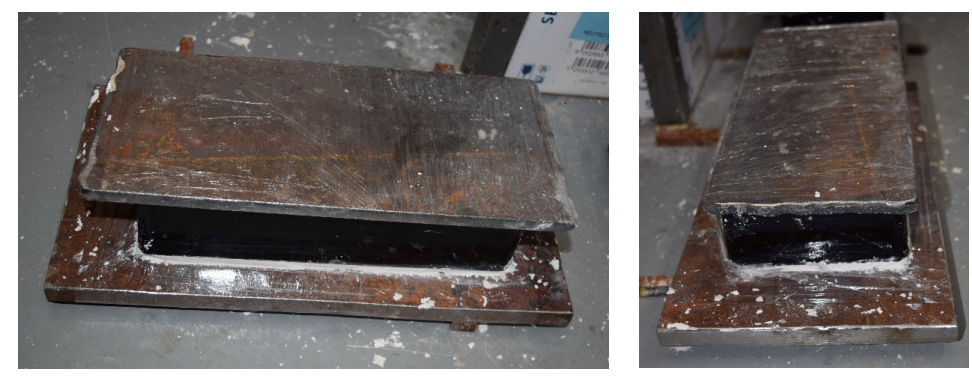

Figure 5. Compression test specimens

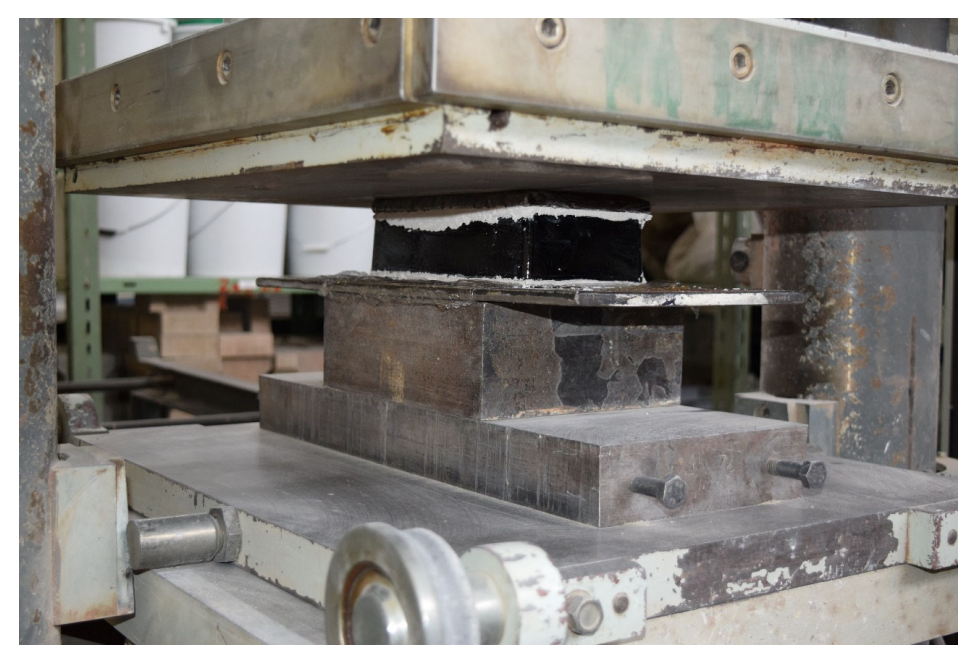

Figure 6. Test specimen in the testing machine

\section{Results}

\section{Three-point bending flexural test}

Since the tensile strength of the glass is approximately ten times lower than the compressive strength, the crack always occurs on the tensile side of the test specimen as demonstrated by the performed experiments. In all cases a crack was created at the middle of the span, no crushing of the glass was observed near the supports neither near loading point, see Figure 7. The section modulus, used to determine tensile strength, was calculated after test from the dimensions measured in the rupture cross-section. The modulus of elasticity was calculated based on the values of the relative strains from the strain gauge and the deflection in the middle of the span. Figure 8 shows broken test specimens after test. Load-displacement diagrams for all tested bricks are in Figure 9. The results for all specimens are summarized in Table 1.

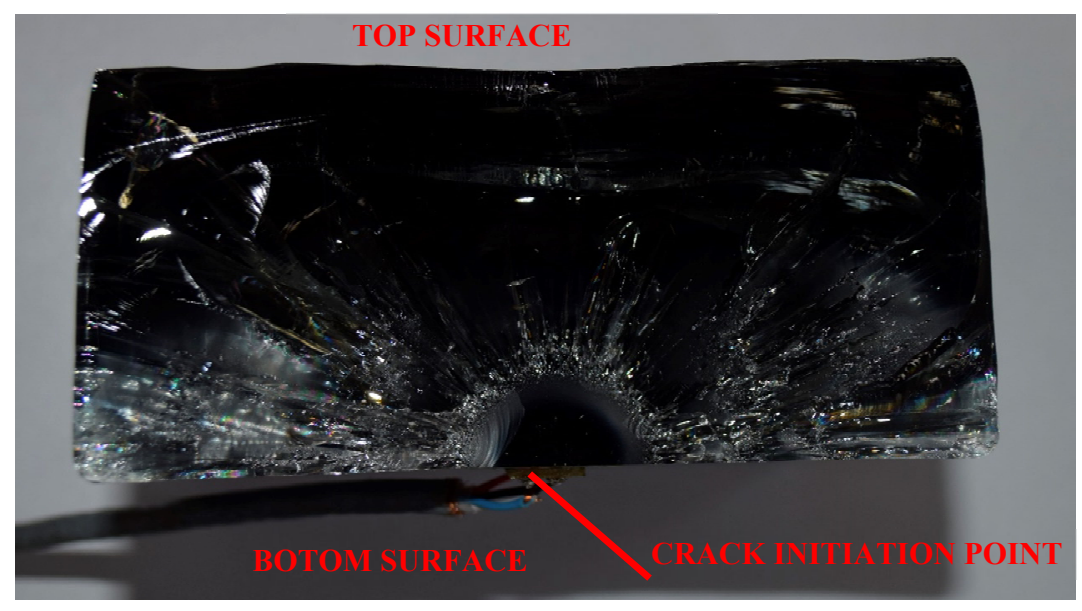

Figure 7. Example of a typical damage 
Table 1. Bending flexural tests results

\begin{tabular}{|c|c|c|c|c|}
\hline \multirow{2}{*}{ Specimen number } & $\begin{array}{c}\text { Maximal deflection } \\
\delta_{\max }\end{array}$ & $\begin{array}{c}\text { Failure load } \\
F_{\max }\end{array}$ & $\begin{array}{c}\text { Failure stress } \\
\sigma_{\max }\end{array}$ & $\begin{array}{c}\text { Modulus of elasticity } \\
\text { E }\end{array}$ \\
\cline { 2 - 5 } & $\mathrm{mm}$ & $\mathrm{kN}$ & $\mathrm{MPa}$ & $\mathrm{GPa}$ \\
\hline H-01 & 0.244 & 74.669 & 65.01 & 74.49 \\
\hline H-02 & 0.251 & 81.268 & 79.31 & 82.61 \\
\hline H-03 & 0.175 & 71.848 & 70.44 & 89.49 \\
\hline H-04 & 0.242 & 82.193 & 60.62 & 76.05 \\
\hline H-05 & 0.204 & 59.958 & 56.20 & 69.14 \\
\hline H-06 & 0.239 & 64.275 & 55.01 & 75.80 \\
\hline
\end{tabular}
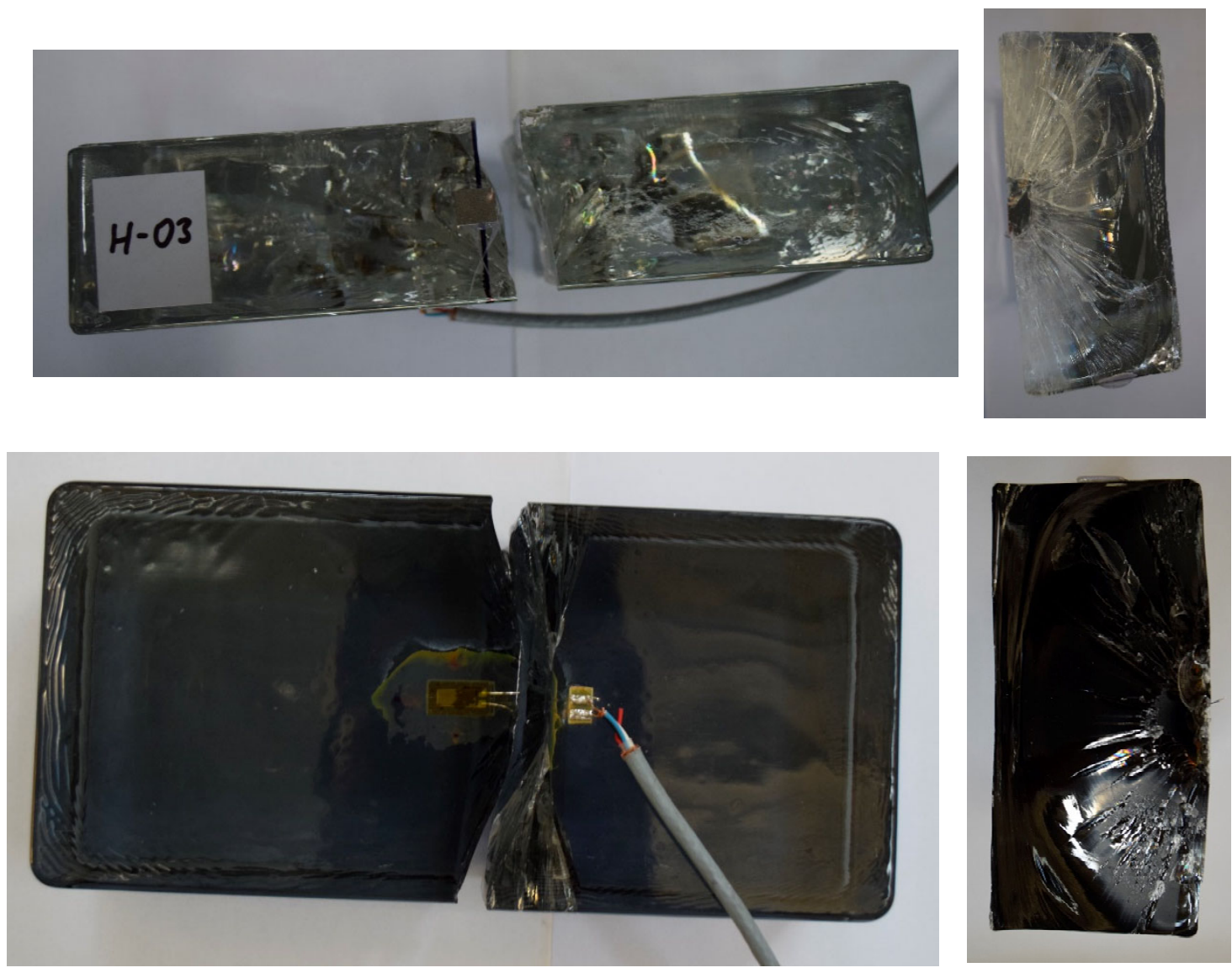

Figure 8. Specimens after test

Table 2. Compression tests results

\begin{tabular}{|c|c|c|c|c|}
\hline \multirow{2}{*}{ Specimen number } & $\begin{array}{c}\text { Failure force } \\
\mathrm{F}_{\text {fail }}\end{array}$ & $\begin{array}{c}\text { Failure stress } \\
\sigma_{\text {fail }}\end{array}$ & $\begin{array}{c}\text { Maximal force } \\
\mathrm{F}_{\max }\end{array}$ & $\begin{array}{c}\text { Maximal stress } \\
\sigma_{\max }\end{array}$ \\
\cline { 2 - 5 } & $\mathrm{kN}$ & $\mathrm{MPa}$ & $\mathrm{kN}$ & $\mathrm{MPa}$ \\
\hline $\mathrm{C}-01$ & 2600 & 94.6 & 3645 & 132.6 \\
\hline $\mathrm{C}-02$ & 1900 & 69.1 & 2260 & 82.2 \\
\hline $\mathrm{C}-03$ & 450 & 16.4 & 1600 & 58.2 \\
\hline
\end{tabular}




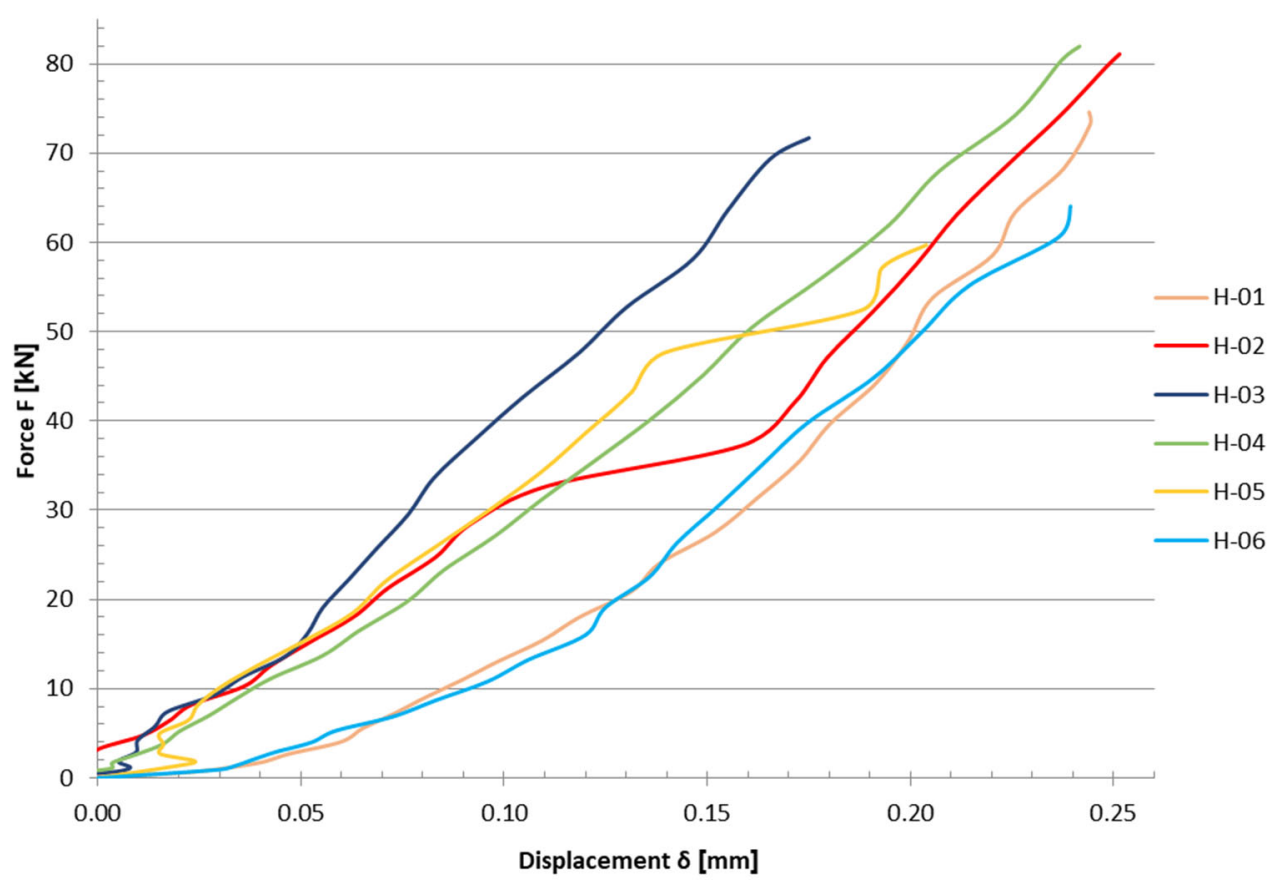

Figure 9. Load-displacement diagrams

\section{Compression test}

Manufacturer of the glass bricks declare maximal compressive strength as $109 \mathrm{MPa}$. In all cases, the first break of the glass brick did not cause a reduction of the load force. After the first crack in the glass, the test specimen was further loaded. As the force increased, the cracks developed further until the brick collapsed. The test was terminated by disintegration of test specimens at maximum force. The results for all specimens are summarized in Table 2, where $F_{\text {fail }}$ represents the forces in the formation of the first crack, and $F_{\max }$ the maximum force that was attained during the collapse. Figure 10 show the specimen after the compression test.
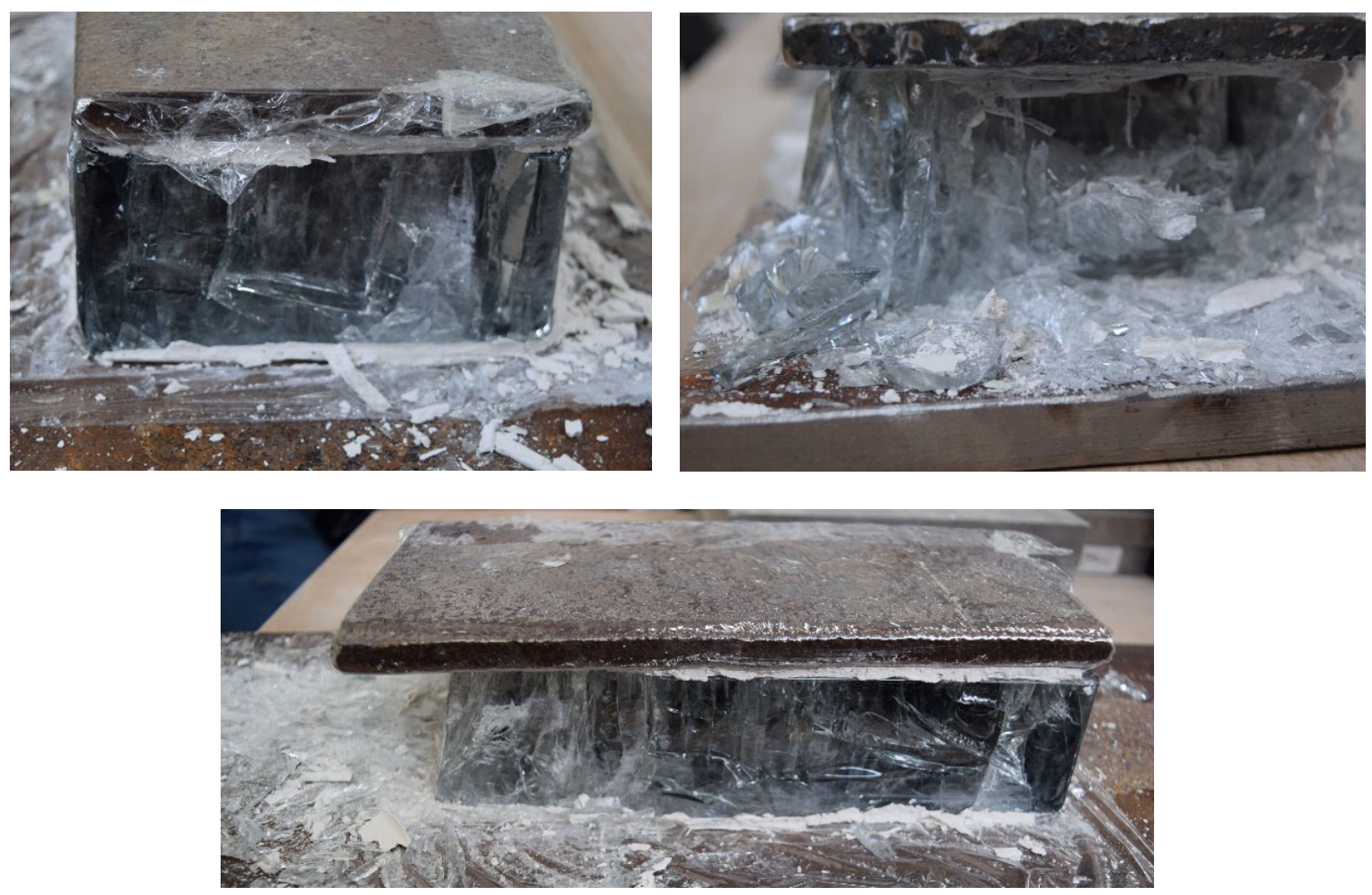

Figure 10. Specimens after test 


\section{Discussion}

The modulus of elasticity of float glass used in building industry is generally reported in the literature (Fanderlík, 1996; Wurm, 2007) as approximately $70.00 \mathrm{GPa}$. The average value of the elastic modulus based on the performed experiments is $75.80 \mathrm{GPa}$, which shows that the glass bricks have a modulus of elasticity approximately the same as the float soda-lime-silica glass. The failure of glass bricks loaded by three-point bending occurred always in the middle of the span at the bottom surface that was subjected to tension.

The measured values of the compressive strength exhibited considerable scattering and the difference against the declared strength was not negligible. In addition, it is debatable which value can be considered as a load-bearing capacity, since the first crack already caused a significant destruction of the brick, but the brick was still able to carry increasing loads up to reaching the maximal force. Differences between the values of the compressive strength can be caused by several different influences. In the case of glass, the failure occurs most often due to the exceeding of the strength at the local peak of stress. This can be caused, for example, by a larger grain in the gypsum bed, contaminant in the glass, difference in residual stresses in the glass from cooling, or by damage of the surface (scratching, even invisible by human eye).

According to the assumption, the failure always occurred suddenly without prior warning and the brittle failure was accompanied by a pronounced loud sound.

\section{Conclusions}

The aim of this research was to determine the mechanical properties of glass bricks and check the compressive strength declared by its manufacturer. It has been shown that glass bricks have properties very similar to float glass values. Measured values of compressive strength showed a significant difference to the declared value, so that in the future will need further series of tests with a large number of specimens. Obtained data will be used in the follow-up research as an input to the numerical model of glass brick masonry.

\section{Acknowledgements}

This research was supported by grant CTU No. SGS18/168/OHK1/3T/11 and by grant No. GA18-10907S of the Czech Science Foundation. In addition, the authors are grateful to company Vitrablok, s.r.o. for the co-operation and providing the glass bricks for the experiments.

\section{References}

Christoph, P., \& Knut, G. (2008). Innovative Glass Joints - The 11 March Memorial in Madrid. In F. Bos, C. Louter, \& F. Veer (Eds.), Challenging Glass: Conference on Architectural and Structural Applications of Glass. Delft, the Netherlands p. 113/668. IOS Press, The Netherlands.

Fanderlík, I. (1996). Vlastnosti skel. Praha: Informatorium (in Czech).

Fíla, J., Eliášová, M., \& Sokol, Z. (2017). Glass masonry - Experimental verification of bed joint under shear. In IOP Conference Series: Materials Science and Engineering (pp. 251-257). https://doi.org/10.1088/1757-899X/251/1/012097

Fíla, J., Eliášová, M., \& Sokol, Z. (2018). Experimental investigation of mortar mechanical properties for glass brick masonry. Glass Structures and Engineering, 4(1), 127-141. https://doi.org/10.1007/s40940-018-0085-6

Oikonomopoulou, F., Bristogianni, T., Veer, F., \& Nijsse, R. (2017). The construction of the Crystal Houses façade: challenges and innovations. Glass Structures and Engineering, 3(1), 87-108. https://doi.org/10.1007/s40940-017-0039-4

Wurm, J. (2007). Glass structures. Birkhäuser, Basel - Boston - Berlin. 